\title{
PENDIDIKAN ERA KOLONIAL DALAM NOVEL SIEDJAH KARYA NICO VINK (KAJIAN SOSIOLOGI SASTRA)
}

\section{COLONIAL ERA EDUCATION IN SIEDJAH NOVEL WRITTEN BY NICO VINK (LITERARURE SOCIOLOGY STUDY)}

\author{
Tsalits Abdul Aziz Al Farisi* \\ Pendidikan Bahasa dan Sastra Indonesia, Universitas Islam Darul Ulum Lamongan, \\ Indonesia \\ $\frac{\text { drumbig_tsalis@yahoo.co.id }}{\text { *penulis korespondensi }}$
}

\begin{tabular}{ll}
\hline Info Artikel & ABSTRAK \\
\hline Sejarah artikel: & Penelitian ini bertujuan untuk mendeskripsikan potret pendidikan, fakta \\
Diterima: & sejarah, latar belakang sosial budaya masyarakat, dan nilai-nilai pendidikan \\
19 November 2020 & yang terkandung dalam novel Siedjah karya Nico Vink. Penelitian ini \\
Direvisi: & merupakan penelitian deskriptif kualitatif dengan metode content analysis \\
24 Desember 2020 & atau analisis isi. Metode penelitian yang digunakan dalam penelitian ini \\
Disetujui: & adalah metode deskriptif kualitatif. Metode ini menghasilkan data deskriptif \\
20 Januari 2021 & berupa data tertulis maupun lisan tentang nilai-nilai pendidikan dalam unsur \\
& sosiologi. Metode ini digunakan untuk menelaah isi dari suatu dokumen. \\
Kata kunci: & Dokumen dalam penelitian ini adalah novel Siedjah karya Nico Vink. \\
Siedjah, Nico Vink, & Dalam hal ini peneliti mendeskripsikan data yang berkaitan dengan nilai- \\
nilai pendidikan, & nilai pendidikan dalam lingkup sosiologi sastra. Hasil temuan dalam \\
sosiologi sastra, & penelitian ini meliputi nilai-nilai pendidikan pada era kolonialisme yang \\
kolonialisme & berangkat dari fakta sejarah yang diceritakan ulang oleh tokoh utama \\
& Siedjah. Tokoh utama memandang sistem kolonialisme merupakan sistem \\
& terpadu yang dilakukan untuk kepentingan tertentu demi menaikkan citra \\
& sosial yaitu sebagai kaum pendidik.
\end{tabular}

\begin{tabular}{|c|c|}
\hline Article Info & ABSTRACT \\
\hline $\begin{array}{l}\text { Article history: } \\
\text { Received: } \\
\text { 19 November } 2020 \\
\text { Revised: } \\
\text { 24 December } 2020 \\
\text { Accepted: } \\
\text { 20 January } 2021 \\
\text { Keyword: } \\
\text { Seidjah, Nico Vink, } \\
\text { Education Values, } \\
\text { Sociology of Literature, } \\
\text { Colonialism }\end{array}$ & $\begin{array}{l}\text { This study aims to describe the portrait of education, historical facts, the } \\
\text { socio-cultural background of the community, and the educational values } \\
\text { contained in the novel Siedjah written by Nico Vink. This research is a } \\
\text { qualitative descriptive study using content analysis method. The research } \\
\text { method used in this research is descriptive qualitative method. This method } \\
\text { produces descriptive data in the form of written and oral data about the } \\
\text { values of education in sociological elements. This method is used to } \\
\text { examine the contents of document. The document in this research is the } \\
\text { novel Siedjah by Nico Vink. In this case, the researcher describes the data } \\
\text { related to the values of education in the sociology of literature. The findings } \\
\text { in this study include the values of education in the colonialism era, which } \\
\text { begin from historical facts that are retold by the main character Siedjah. The } \\
\text { main character views the colonialism system as an integrated system carried } \\
\text { out for certain interests in order to raise the social image, namely as } \\
\text { educators. }\end{array}$ \\
\hline
\end{tabular}
DOI: http://dx.doi.org/10.30651/st.v14i1.6472 


\section{PENDAHULUAN}

Karya sastra tentu tidak
terlepas dari sisi sosial yang melatarbelakangi sikap penulis sebagai pusat pencerita. Dalam hal ini, karya sastra juga memotret sisi sejarah yang diangkat melalui fakta-fakta sosial masa lalu (Damono, 2020). Novel siedjah berawal dari potret kolonial yang diceritakan kembali secara terstruktur. Pola tersktruktur ini ditulis dari peristiwa awal tokoh utama Siedjah dari sejak lahir hingga dia diangkat sebagai guru sekolah di Hindia Belanda. Penelitian tentang nilai pendidikan dalam novel pernah dilakukan oleh Irma (2018). Penelitian tersebut memfokuskan pada komponen pendidikan karakter yang meliputi: (1) hidup sederhana, (2) tanggung jawab, (3) kasih sayang, (4) berbakti kepada orang tua, (5) religius, (6) peduli, (7) menghargai prestasi, (8) kerja keras, (9) cinta tanah air, (10) jujur, (11) empati dan gemar belajar. Penelitian berupa jurnal tersebut berupaya untuk menyampaikan tentang nilai pendidikan yang lebih dominan muncul dalam sebelas komponen tersebut. Kemunculan tersebut bertujuan untuk menemukan ciri khas dari tujuan dan temuan penelitian. Hal tersebut tidak jauh berbeda dalam penelitian tentang novel Siedjah yang bersudut pandang pada pendidikan era kolonial. Namun Siedjah lebih memfokuskan pada sistem pada zaman tertentu. Sementara penelitian sebelumnya lebih ke struktur pendidikan dalam sebelas komponen nilai pendidikan.

Penelitian tentang pendidikan dalam novel juga dilakukan oleh Santosa (2012). Penelitian ini memiliki ciri khas yang lebih kompleks perihal sudut pandang pendidikan dalam ranah kombinasi teori. Fokus yang ditemukan dalam penelitian ini adalah fase pendidikan era kolonial dalam sudut pandang pragmatik. Artinya, penelitian ini berupaya untuk menemukan narasi tokoh yang berkaitan dengan tindak sosial pendidikan pada tiga novel dalam hal pendidikan kaum priyayi.

Pada novel Siedjah peneliti berupaya untuk mengembangkan penelitian sebelumnya melalui sudut pandang sosiologi sastra dengan alasan kedudukan sosiologi sangat luas jangkauannya termasuk nilai-nilai pendidikan. Ciri khas penelitian novel Siedjah terhadap penelitian sebelumnya terletak pada pengembangan pada sudut pandang teori sosiologi. Perihal teori sosiologi tentu saja tidak terlepas dari sikap pengarang dalam kreator fiksi.

Pengarang novel memiliki kedudukan sentral dalam menceritakan narasi sejarah yang terdapat dalam novel Siedjah. Penulis menceritakan kembali kisah ibunya (Siedjah) yang saat itu pernah singgah di Hindia Belanda. Kedudukan kolonial menurut novel Siedjah terbatas pada penyampaian ulang peristiwa (flasback) tokoh utama masa lalunya ketika ia singggah ke Hindia Belanda. Niko Vink menceritakan peristiwa sistem pendidikan dari kacamata sosial yang menurut penulis sungguh bernuansa politis, dalam hal ini dimaknai sebagai kebijakan yang tidak adil bagi masyarakat kelas bawah yang pada puncaknya dapat disebut sebagai sistem kolonial.

Sistem kolonial merupakan suatu sistem di mana suatu negara menguasai rakyat dan sumber daya negara lain tetapi masih tetap berhubungan dengan negara asal (Lomba, 2016), artinya ada semacam pemindahan sistem pemerintahan 
suatu negara ke negara lain dimana sistem ini bertujuan untuk mewujudkan cita-cita kekuasaan suatu bangsa. Pada novel ini, cita-cita pemindahan kekuasaan tersebut digambarkan dalam sistem dan nilai pendidikan.

Sosiologi sastra dalam karya sastra menampilkan gambaran kehidupan, dan kehidupan adalah suatu kenyataan sosial (Damono, 2020). Penampakan kenyataan, bagi Aristoteles, tidak semata-mata menjiplak kenyataan, melainkan merupakan sebuah proses kreatif novelis, cerpenis maupun penyair sambil bertitik pangkal pada kenyataan menciptakan sesuatu melalui mimesis, pengarang menciptakan kembali kenyataan dari pengalaman, pemikiran, sekaligus apa yang dibayangkan oleh dirinya atau orang lain. Berangkat dari kenyataan yang tampak sebagai sejumlah unsur yang masih kacau balau, pengarang memilih beberapa unsur lalu menyusunnya menjadi suatu gambaran yang dapat dimengerti, atau dengan kata lain, kebenarannya yang universal, yang berlaku dimana-mana dan pada segala zaman (Ratna, 2003). Karena itu, menurut Aristoteles, sastra lebih bermutu daripada penulisan sejarah yang hanya menampilkan fakta. Kebermutuan ini, disamping penampilan suatu peristiwa kongkret, dalam sastra juga dibeberkan suatu pandangan umum yang luas. Nico Vink berhasil menyampaikan sejarah dalam nuansa sastra yaitu meramu sistem bahasa yang memiliki nilai estetika yang tinggi.

Konteks sastra sebagai cermin hanya merefleksikan keadaan pada saat tertentu. Istilah "cermin" ini akan menunjuk pada berbagai perubahan dalam masyarakat (Endraswara, 2004)
Perubahan dan cara individu bersosialisasi biasanya akan menjadi sorotan pengarang yang kemudian dipantulkan melalui karyanya, tanpa terlalu banyak diimajinasikan. Karya sastra yang cenderung memantulkan keadaan masyarakat, mau tidak mau akan menjadi saksi zaman. Dalam kaitan ini, pengarang ingin mendokumentasikan zaman dan sekaligus sebagai alat komunikasi antara pengarang dengan pembacanya meskipun tidak secara langsung. Sosiologi sastra digunakan sebagai sudut pandang berfikir dari nilai-nilai pendidikan karena sosiologi bersifat komunal dalam hal menganalisis perilaku masyarakat salah satunya pembelajaran. Perubahan sikap, watak masyarakat dipengaruhi oleh perilaku lingkungan (pendidikan) yang kelak akan menjadi perkembangan budaya yang terjadi di masyarakat. Nico Vink berupaya untuk menyampaikan situasi pendidikan masyarakat era kolonial dari sudut pandang sketsa pada tiaptiap daerah yang ia singgahi dan dia wujudkan sebagai lakon utama yang bernama Siedjah. Tokoh utama Siedjah sebagai subjek kreator menyampaikan banyak hal terhadap lingkungannya. Dalam hal ini sosiologi sastra menjadi ukuran penelitian mengingat dominasi kisah yang menampilkan beragam peristiwa dari masing-masing daerah (budaya).

Karya sastra, baik sebagai kreativitas estetis maupun respons kehidupan sosial, mencoba mengungkapkan perilaku manusia dalam suatu komunitas yang dianggap berarti bagi aspirasi kehidupan seniman, kehidupan manusia pada umumnya. Karena itulah dimensidimensi yang dilukiskan bukan hanya entitas tokoh secara fisik, tetapi sikap dan perilaku, dan kejadian-kejadian 
yang mengacu pada kualitas struktur sosial (N. K. Ratna, n.d.). Struktur sosial tersebut meliputi pengalaman sosial baik secara langsung maupun pengalaman membaca karya sastra yang lain, salah satunya karya yang bernuansa sejarah.

Nilai pendidikan dalam sebuah karya sastra terjadi akibat perenungan seorang penulis untuk menciptakan nilai-nilai tertentu perihal konsep pendidikan dalam sebuah cerita. Nilai tersebut menimbang fungsi atau tidaknya karya sastra terhadap masyarakat sebagai pembaca (Lorens, 2002). Maka dari itu, nilai pendidikan dalam karya sastra lahir tidak hanya berangkat dari nilai-nilai pengalaman penulis tetapi pengalaman penulis terhadap sejarah juga patut menjadi perhatian dengan tujuan untuk menanamkan nilai patriotisme masyarakat pembaca.

\section{METODE}

Metode penelitian yang digunakan dalam penelitian ini adalah metode dskriptif kualitatif. Metode ini menghasilkan data deskriptif berupa data tertulis maupun lisan tentang nilai-nilai pendidikan dalam unsur sosiologi (Moeloeng, 2008). Metode deskriptif berupaya untuk mengurai masalah dalam sebuah penelitian melalui fakta-fakta sosial salah satunya sejarah dalam teks (sastra).

Penelitian ini merupakan penelitian deskriptif kualitatif dengan metode content analysis atau biasa disebut sebagai analisis isi. Metode ini digunakan untuk menelaah isi dari suatu dokumen (teks sastra). Adapun teks-teks yang akan dideskripsikan dalam penelitian ini adalah nilai pendidikan, pandangan dunia pengarang sebagai pelaku sejarah. Teknik pengumpulan data yang digunakan dalam penelitian ini adalah analisis dokumen yang diawali dari pembacaan, pencatatan dokumen dan analisis dokumen.

\section{HASIL DAN PEMBAHASAN Siedjah Dalam Potret Sejarah}

Pada dasarnya novel Siedjah karya Nico Vink ini bercerita tentang tokoh utama (siedjah) yang membaca semua tempat yang ia singgahi sebagai peristiwa sejarah yang hebat. Dinamika sosial dan perdebatan batin tokoh utama memunculkan nuansa historis sekaligus nilai sosial dan budaya tempat tokoh utama singgahi. Siedjah lahir di Bremer Belanda pada 23 September 1899 dengan nama Siebrigje. Kemudian setelah singgah di Hindia Belanda nama tersebut diubah menjadi Siedjah agar tampak seperti masyarakat lokal Jawa. Siedjah lahir dari keluarga kristen yang taat secara etika maupun politik. Tetapi dari segi struktur sosial keluarganya sangat menentang ajaran komunis. Karena menurut Siedjah ajaran komunis sangat bertentangan dengan ajaran agama yang dianutnya, meskipun terkadang komunis kerap memberikan keuntungan materi bagi dirinya. Tetapi dia berupaya menjaga jarak terhadap sistem komunis dan hanya mengambil hikmah dari lahirnya sistem tersebut sebagai bentuk wawasan pembelajaran yang kelak menjadikan dia seorang guru di Hindia Belanda.

Perjalanan tokoh utama dimulai dari Marseille Prancis yang saat itu sedang bergejolak perang dunia ke I dia ceritakan ulang sebagai bentuk flashback nilai-nilai sosial yang mengubah peradaban dunia pasca perang. Perubahan tersebut membentuk watak tokoh utama 
menjadi manusia yang memiliki wawasan budaya yang luas.

"Tahun 1914 sampai 1918, aku belajar di sekolah guru. Tahun-tahun itu termasuk dalam masa Perang Dunia I. Karenanya, masa itu tidak bisa disebut sebagai tahun-tahun biasa. Dan aku kembali mengenali aspekaspek tipikal dari jiwa dan kebudayaan Belanda". (Vink, 2020)

Siedjah berkenalan dengan lingkungan dan budaya saat itu berawal dari pengamatannya yang kemudian ia fahami sebagai titik tolak edukasi terhadap dirinya sendiri bagaimana pekembangan budaya yang suatu saat akan menjadi sejarah yang perlu diungkapkan. Freire dalam bukunya yang berjudul Pendidikan kaum tertindas pernah mengatakan bahwasanya sejarah punya peran penting dalam mencetak sikap pembelajaran maupun guru dalam menyampaikan suatu peristiwa (Freire, 2008). Pandangan tersebut membuktikan bahwasanya sejarah dapat bermanfaat dari sisi pengembangan intelektual budaya dan nilai sosial karena tokoh utama berinteraksi terhadap pergolakan batin dia melihat situasi sosial budaya maupun pendidikan era kolonial yang menurutnya tidak seimbang.

\section{Penanaman Budaya Literasi} Tokoh utama Siedjah digambarkan sebagai sosok yang gemar membaca. Kegemaran membaca ini bertujuan terhadap citacitanya sebagai tenaga pendidik untuk bekal mengajarkan anak-anak di Hindia Belanda. Selama perjalanan menuju Hindia Belanda Siedjah memanfaatkan perpustakaan kapal untuk membaca beraneka macam buku sejarah Hindia Belanda mulai dari tataran sosial maupun budaya yang mempengaruhi ideologi masyarakatnya.

"Koleksi buku di perpustakaan Patria cukup menarik. Bukubuku tentang pelayaran, perkapalan dan tentang Hindia belanda menghilangkan kejemuan. Aku menikmati dan banyak belajar dari ceritacerita yang dikisahkan oleh berbagai pengarang kelahiran Hindia Belanda”. (Vink, 2020)

Siedjah menanamkan budaya literasi/membaca menjadi penting karena seorang guru sangat perlu membekali dirinya melihat luas sketsa budaya asing. Budaya yang belum pernah dia pahami. Penanaman membaca sejarah menurut Siedjah sangat dibutuhkan mengingat cerita ini berupaya untuk menunjukkan sistem politik pendidikan dan kolonialisme saat itu di Hindia Belanda yang menurut sejarah terjadi selama 300 tahun. Siedjah tidak menggurui masyarakat agar belajar kebudayaan lain, tetapi siedjah mengajak masyarakat Hindia Belanda untuk kritis terhadap kebijakan yang ditanamkan oleh pemerintah Belanda saat itu. Pada novel ini sikap kritis ditujukkan untuk memahami pentingnya pendidikan sejarah bagi perkembangan masa depan.

\section{Pendidikan Era Kolonial}

Pendidikan lahir karena masyarakat memiliki tujuan untuk mengembangkan potensi berpikir manusia agar kelak dapat membuat aturan dan mengatur budaya sosial 
yang ada di lingkungannya (Freire, 2007). Hal tersebut bisa jadi menjadi tujuan Nico Vink sebagai penulis untuk menunjukkan bagaimana rezim kolonial dalam menciptakan ruang edukasi yang bersifat politik praktis. Tokoh utama diperankan sebagai seorang guru yang mengalami perjalanan maupun pergolakan batin yang luar biasa ketika dihadapkan kepada nilai-nilai sejarah di tempatnya ia bekerja di Hindia Belanda. Sebagai salah satu contoh dalam novel ini, tokoh siedjah ketika tiba di tanah Jawa dia melihat ada suatu kelas tertentu yang diciptakan oleh politik kolonial.

\section{"Dunia orang Belanda dan orang pribumi masih tetap dua dunia yang terpisah, saling berhadapan, saling bertentangan. Keduanya merupakan dua dunia yang hidup sendiri-sendiri. Bila memang begitu, maka memang seharusnya begitu. Barangkali Batavia berpikir demikian. Aku melihat di sekelilingku di Batavia. Kulihat berlakunya apartheid kolonial. Lihatlah pemisahan kelas orang Belanda dan orang pribumi di dalam trem”. (Vink, 2020)}

Pemisahan kelas dalam skala sosial saat itu sangat mempengaruhi sikap sosial tokoh utama dalam hal mengajar. Karena tokoh utama berpandangan kepada dirinya sendiri sebagai orang yang lahir di tanah kolonial Belanda. Tetapi dia berupaya untuk tetap terjaga dalam situasi diri sebagai seorang guru yang berkewajiban untuk memberi informasi dan edukasi positif kepada semua kelas masyarakat.
Ada yang menarik dalam novel ini ketika tokoh utama sangat menggemari karya Max Havelaar Multatuli yang dia jadikan pedoman untuk mengajar di Hindia Belanda.

"Buku kesukaanku adalah
karya Multatuli, Max Havelaar
of de koffieveliengen der
Nederlandsche

Handelmaatschappij.

$A k u$ menyebutnya 'Max Havelaarku'. Buku itu sangat tajam menentang kesewenangwenangan di masa penjajahan Hindia Belanda. Mengharukan dan jenaka. Asisten Residen di Lebak, Jawa Barat mengucapkan pidato luar biasa soal penindasan terhadap orang Sunda dan Jawa. Tentang masa depan suram penduduk biasa dan tentang para pegawai Pemerintah dalam Negeri hindia Belanda yang hanya melihat saja tanpa berbuat apaapa”.

Nico Vink berupaya untuk membuka wawasan tentang bagaimana pentingnya Max Havelaar dalam Multatulinya membuka mata batin kita untuk melihat bagaimana sistem sosial saat itu yang sangat tidak berpihak kepada masyarakat pribumi. Pola ketidakadilan juga menyusup dalam sistem pembelajaran yang cenderung dipaksakan hadir dan diarahkan untuk kepentingan kolonial. Kepentingan ini untuk memperluas jaringan rezim mereka agar tetap terjaga meskipun pemberontakan masyarakat pribumi tetap gencar melawan kolonial. Posisi menjajah dan menggurui dalam novel ini tampak sumblim perihal sikap Nico Vink dalam menggambarkan situasi 
pendidikan era kolonial. Terkadang Nico Vink juga menyampaikan pentingnya sejarah untuk mempertahankan nilai-nilai budaya yang sudah ada. Tetapi di sisi lain pola penyampaian nilai-nilai pendidikan bercampur aduk dengan sejarah kolonial cenderung membangkitkan kembali semangat kolonial. Tapi semua dapat ditangkis oleh NicoVink dengan sikap yang tegas bahwasanya sejarah tetap penting bagi nilai pendidikan masa depan meskipun sejarah dapat memutar ulang kembali nilai-nilai semangat kolonial.

\section{Dampak Positif dan Negatif Pendidikan Era Kolonial}

Pendidikan era kolonial tidak semata memiliki nilai negatif dari sudut pandang kebijakan, keteraturan yang berkesinambungan dengan sistem pembelajaran saat itu. Novel Siedjah menggambarkan perilaku disiplin perihal mengisi waktu luang untuk belajar, memahami makna dari setiap tempat yang disinggahi oleh tokoh utama (Siedjah). Meskipun Siedjah mengalami banyak tekanan sosial perihal peristiwa sikap Belanda mengagresi masyarakat Hindia Belanda untuk belajar dengan gaya selingkung kolonial, tetapi masyarakat saat itu tetap terjaga pada konsistensi kearifan lokal yang tetap dipertahankan. Perilaku inilah yang menjadi suri tauladan menurut Siedjah ketika dia berada di Hindia Belanda. Siedjah menganggap masyarakat Hindia Belanda pantas dijadikan sebagai ukuran sikap mempertahankan nilai leluhur (kearifan lokal) meskipun banyak ancaman dari pihak Belanda untuk menuntut masyarakat untuk mengikuti kebijakan sosial yang diterapkan oleh Belanda.
Hal tersebut dapat kita kaitkan dengan pendapat Freire mengenai konsep kekuasaan dalam pendidikan yang menganggap bahwa kekuasaan bekerja pada dan melalui masyarakat (Freire, 2007). Di satu sisi, dominasi tidak sepenuhnya mutlak. Kekuasaan bersifat ekslusif dan sebagai kekuatan negatif. Di sisi lain, kekuasaan merupakan daya dorong bagi semua perilaku manusia di mana masyarakat mempertahankan hidupnya, terus berjuang dan berusaha mewujudkan cita-cita kehidupannya yang lebih baik.

\section{PENUTUP}

Novel Siedjah berupaya untuk memotret bagaimana sistem pendidikan pada masa kolonial Belanda yang bernuansa politik. Ketidakseimbangan kelas sosial menjadi wujud utama dalam membuat kebijakan. Pendidikan menjadi penting pada masa kolonial karena pendidikan berupaya untuk mengubah budaya pribumi menjadi budaya baru yang dimiliki oleh orangorang yang punya kekuasaan saat itu. Nico Vink menyadari bahwasanya pendidikan sejarah perlu untuk menjaga kedisiplinan belajar dan melestarikan budaya pribumi jangan sampai ada campur tangan budaya lain. Namun, tentu pendidikan tidak terlepas dari sudut pandang budaya lain mengingat ilmu pengetahuan sangatlah luas. Budaya asing hanya sebagai wawasan eksternal sebagai tolok ukur pembanding dengan budaya pribumi. Suatu saat hasil pembanding tersebut dalam Siedjah akan menghasilkan perkembangan baru dalam ranah pendidikan.

\section{DAFTAR PUSTAKA}

Damono, Sapardi Djoko. (2020). Sosiologi Sastra, Sebuah 
Pengantar Ringkas. Jakarta: Gramedia.

Endraswara, Suwardi. (2004). Metodologi Penelitian Sastra (Epistemologi, Model, Teori dan Aplikasi. Yogyakarta: Pustaka Widyatama.

Freire, P. (2007). Politik Pendidikan: Kebudayaan, Kekuasaan dan Penindasan. Yogyakarta: Pustaka Pelajar.

Freire, P. (2008). Pendidikan Kaum Tertindas. Jakarta: LP3ES.

Irma, Nurika C. (2018). Nilai-Nilai Pendidikan Karakter Dalam Novel Ibuk Karya Iwan Setyawan. RETORIKA: Jurnal Bahasa, Sastra, Dan Pengajarannya, 11(1), 14. https://doi.org/10.26858/retorika. v11i1.4888

Lomba, Ania. (2016). Kolonialisme, Pascakolonialisme. Narasi Press.
Lorens, B. (2002). Kamus Filsafat. Jakarta: Gramedia Pustaka.

Moeloeng, Lexy. (2008). Metodologi Penelitian Kualitatif. Bandung: Remaja Rosdakarya.

Ratna, Nyoman Kutha. (2003). Paradigma Sosiologi Sastra. Yogyakarta: Pustaka Pelajar.

Santosa, W. H. (2012). Nilai-Nilai Kepriyayian Jawa Dalam NovelNovel Para Priyayi , Canting, dan Sosiopragmatika (Javanese Aristocracy Values in Para Priyayi, Canting, dan Gadis Tangsi Novels: a Study on Culture, Ideology and SocioPragmatics). Jurnal Pengajian Melayu, 23(2), 257-275.

Vink, N. (2020). Siedjah. Jakarta: Yayasan Pustaka Obor. 